briefly the varied products from the forest, not only timber as such and as a source of cellulose, but also bamboos, fibres, gums, resins, medicines, fodder, etc. Then follows a brief but interesting discussion of the history of forest clearance to provide agricultural land, for timber products, and for hygienic purposes, such as an anti-malarial measure and for tsetse control.

Under the title of "Forest Influences" the author outlines the effect of forests on rainfall, water regime including erosion, wind and temperature, as well as a brief reference to the forest as a habitat of animal and plant life. The chapter on "Forest Conservation and Protection" discusses fire protection, control of grazing and protection against animals, insects and fungi, as well as natural agencies such as wind. The next chapter outlines methods of surveying forest resources, methods of extraction of timber, and the preparation of products from sawn timber and pulpwood to wood distillation and resin derivatives. The next three chapters deal with sylvicultural techniques used in the natural and artificial regeneration of woods and their subsequent tending; generalities are spiced with sufficient detail to make them interesting. Under the title of "Growth of Crops", the techniques of the measurement and management of forests are discussed, while the chapter on "Reclamation and Afforestation" draws its examples from the Culbin Sands in Scotland to the papyrus swamps of Uganda. There is a short chapter on forest policy, law, research and education, while the last gives a brief picture of forestry in the United Kingdom.

In the concluding paragraph, the author considers that it is inevitable that there will be a further reduction in the area at present under forest in certain parts of the world, particularly the less developed, but that this loss will be made good, at least in part, by afforestation of land mistakenly cleared of forest and also land not previously woodland, but which can now be made to carry trees by improved techniques, as in Great Britain, and also by improved production per acre. $\mathrm{He}$ has no doubt as to the future of wood as a major world raw material.

This book worthily upholds the reputation of the series for serious but non-technical exposition of $a_{0}$ subject. It is remarkable for the amount and variety of the information that the author has presented so skilfully, concisely and lucidly.

H. M. Steven

\section{MONKEYS AS PETS}

\section{The Monkey Book}

By Ernest P. Walker. Pp. xii +154. (New York : The Macmillan Company, 1954.) 6.50 dollars.

THIS book, by the assistant director of the National Zoological Park at the Smithsonian Institution, Washington, tells the owner or would-be owner of a pet monkey all that he should know. Mr. Walker has not only successfully supervised the keeping of monkeys in captivity for many years, but also has been answering questions on the subject for as long-now he has set forth his experience and knowledge in an attractive volume. The book will be of great value not only to private keepers of pets but also to those concerned with the care of monkeys in zoos and research laboratories.

The work is divided into two parts; the first part deals with general questions of animal management as applied to the primates, and is full of valuable information ranging from feeding, cages, exercise and health to psychology, and what to do when a pet escapes. This is excellent, and the chapter entitled "Psychology", pointing out that the psychological problem of keeping pets happy is of even more importance than the problem of supplying them with food, should be studied by everyone who keeps wild animals in captivity. A sub-section of the first part giving instructions for the maintenance of cultures of mealworms, wax moths and crickets as food for captive animals is particularly helpful.

The second part of the book deals systematically with all the more-or-less valid groups of species of living primates other than man, and a page is devoted to each of the genera recognized by the author, from lemurs and lorises to anthropoid apes. An introduction gives a short explanation of classification and then a brief description is given of representative species of each genus, with notes on distribution, habits and food, and advice on management in captivity, the probability of obtaining specimens from dealers, and the range of market prices. A special feature of the book is the excellent series of illustrations, mostly from photographs but some from drawings, that gives a splendid pictorial guide to the variety of forms throughout the primates.

The author believes that no pet, if properly treated, will give more satisfaction and companionship than a monkey. The instructions for the care of pet monkeys given in this book will enable owners to derive the maximum of enjoyment from their favourites and will prevent the premature loss of many animals.

The book concludes with a well-chosen select bibliography and a full index. It is a pity that its very high price, for a book of its type and size, will put it beyond the reach of many of those pet enthusiasts outside the United States who would benefit most from possessing it.

L. Harrison Matthews

\section{COALFIELDS OF GREAT BRITAIN}

\section{The Coalfields of Great Britain}

Edited by Sir Arthur Trueman. Pp. xi $+396+7$ plates. (London : Edward Arnold (Publishers), Ltd., 1954.) 63s. net.

7 HrS book is a welcome successor, well suited to present-day requirements, of Walcott Gibson's "Coal in Great Britain", the second edition of which appeared in 1927. During the intervening period, many striking advances have been made in the study of the Carboniferous coals and associated strata with which the present book is almost exclusively concerned. More especially, mention should be made of the palæontological results achieved by Sir Arthur Trueman and other well-known workers, and the detailed re-mapping of the coalfields by the geologists of the Geological Survey. Greater precision has been achieved in most branches of the subject, and many of its aspects have been revolutionized by discoveries of recent years, including, it may be added, those of the authors themselves. All this material, old and new, has been dealt with by Sir Arthur Trueman and his expert collaborators with commendable clarity, and also adequately. Indeed, an outstanding feature of the work is its well-balanced presentation of a subject so charged with detail as is coalfield geology. The two needs which the book aims to meet, those of the 